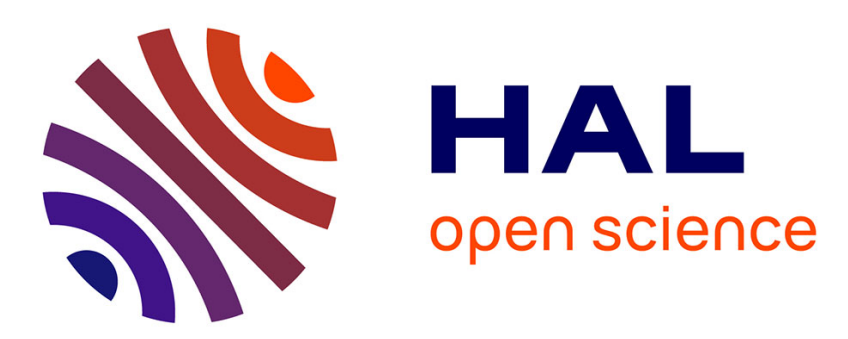

\title{
Energy Recovery DC/AC Converter for Piezoelectric Transformer
}

\author{
Dejan Vasic, François Costa
}

\section{To cite this version:}

Dejan Vasic, François Costa. Energy Recovery DC/AC Converter for Piezoelectric Transformer. 2014 16th European Conference on Power Electronics and Applications (EPE'14-ECCE Europe), Aug 2014, Lappeenranta, Finland. 10.1109/EPE.2014.6910954 . hal-01697581

\section{HAL Id: hal-01697581 https://hal.science/hal-01697581}

Submitted on 31 Jan 2018

HAL is a multi-disciplinary open access archive for the deposit and dissemination of scientific research documents, whether they are published or not. The documents may come from teaching and research institutions in France or abroad, or from public or private research centers.
L'archive ouverte pluridisciplinaire $\mathbf{H A L}$, est destinée au dépôt et à la diffusion de documents scientifiques de niveau recherche, publiés ou non, émanant des établissements d'enseignement et de recherche français ou étrangers, des laboratoires publics ou privés. 


\title{
Energy Recovery DC/AC Converter for Piezoelectric Transformer
}

\author{
Dejan Vasic, François Costa \\ SATIE, UNIVERSud, Université de Cergy-Pontoise \\ Rue d'Eragny, Neuville sur Oise \\ 95031 Cergy-Pontoise, France \\ Tel.: +33 / (0) - 134256891 \\ Fax: +33 / (0) - 147402199 \\ E-Mail: vasic@satie.ens-cachan.fr \\ URL: http://www.satie.ens-cachan.fr
}

\section{Acknowledgements}

The authors are grateful to Eleceram Technology Co., Ltd for providing us with the different types of piezoelectric transducers.

\section{Keywords}

«Piezoelectric transformer», «Recovery energry», «DC/AC converter», «Power supply», «Transducer».

\begin{abstract}
Piezoelectric transformers have been used successfully in DC/AC or DC/DC converter. However, the use of piezoelectric transformers presents a major challenges for power electronic design: the capacitive nature of such devices makes their use delicate as the instantaneous power may be much greater than the average effective power. Due to this challenge, conventional drive circuits, especially inductor, become too bulky. This work describes a converter suitable to drive piezoelectric transformer with low inductor. The proposed converter is a DC/AC structure, which is capable of producing a unipolar square voltage. The circuit provides for recovery of the energy stored on the clamped capacitance back to the primary power supply when the transformer is de-energized. In our design, an auxiliary shunt circuits are connected to the input terminal. The proposed structure of both theoretical and experimental validations has demonstrated the effectiveness of the proposed technique for recovery energy.
\end{abstract}

\section{Introduction}

Piezoelectric transformers (PT) have several advantages compared to conventional magnetic transformers: low housing profile, no winding, high power density, high operating frequency and they are suited for automated manufacturing. However, power electronics for PTs are more complex. The PT requires a switching driving circuit to generate the structure vibration. Due to the capacitive nature of such devices, reactive power and power factor optimization have recently been the subject of numerous investigations [1]-[8]. Accordingly, power converters always need to supply high levels of reactive power, or equivalently high power peaks compared to average power, leading to an overdesign of power amplifiers, especially the magnetic component like inductor. To reduce the switching losses and the high power peaks compared to average power, a wideband zero-voltageswitching (ZVS) half-bridge circuit can be introduced [9]. To achieve the ZVS condition, a bulky inductor or an inductive matching network is typically required in the driving circuit [10]-[16]. However, the added magnetic component sacrifices the size and the weight of the converter. Although an inductor-less half-bridge circuit is possible [17], it only exists in a narrow bandwidth near the resonance frequency of the piezoelectric element, which is not suitable in this application. To overcome this drawback and to recovery energy stored in the clamped piezoelectric capacitance, in this paper, an auxiliary shunt circuit is added at the half-bridge which enables us to decrease this 
reactive energy and the overall size of the power converter. The auxiliary shunt circuit includes two switches and a small inductor. The inductance is not in the path of the major power flow, thus it is not designed with piezoelectric transformer drive frequency. The auxiliary circuit included the return of the electrical energy stored in the piezoelectric clamped capacitance back to the primary power supply when the transformer is turned off. The energy recovery was accomplished with high efficiency by using the resonance between the clamped capacitance and the inductor. This switching shunt technique consists in connecting the piezoelectric transformer to the shunt circuit for a brief time period. This connection leads to a smooth inversion of the piezoelectric voltage, which induces an energy transfer from capacitance to supply source. The consequences of such size reductions involve new opportunities for designing ultra compact, low-cost wide bandwidth power converter with piezoelectric transformers.

The paper is organized as follow: the second section summarizes the electrical behavior and drive requirements of the piezoelectric transformer. In section 3 and 4, the circuit topologies suitable for driving the transformer are presented. Finally, the last section concludes the paper.

\section{Piezoelectric transformer model}

The topology of the piezoelectric transformer is presented in Fig. 1. The PT is a stacked disk-type, operating in thickness mode. The multi-layers structure is composed of 4 input layers and 4 output layers. Primary and secondary layers are made of the same PZT material. Insulation layer is made of glass fiber. Table 1 details the layers thicknesses. The testing specimen was provided by Eleceram Technology Co., Ltd Taiwan.
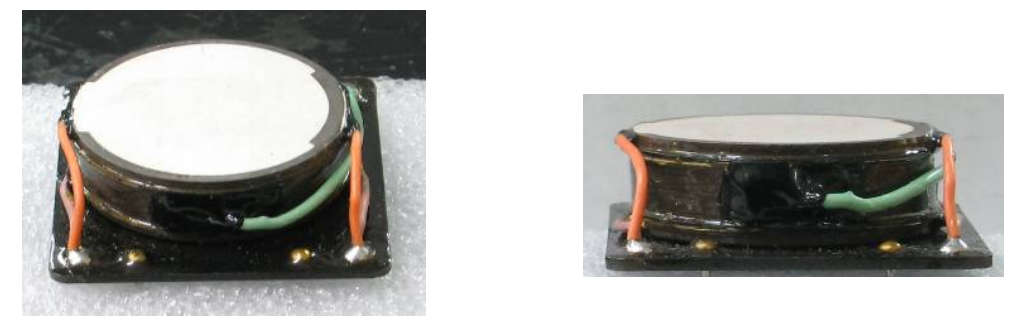

Fig. 1: Pictures of the stacked disk-type piezoelectric transformer operating in thickness mode

Table I: Geometrical Dimensions of the PT

\begin{tabular}{|c|c|c|c|}
\cline { 2 - 4 } \multicolumn{1}{c|}{} & Number of layers & Thickness & Radius \\
\hline Input section & 4 & $0.61 \mathrm{~mm}$ & $13 \mathrm{~mm}$ \\
\hline Output section & 4 & $0.61 . \mathrm{mm}$ & $13 \mathrm{~mm}$ \\
\hline Insulation & 2 & $0.41 \mathrm{~mm}$ & $13 \mathrm{~mm}$ \\
\hline
\end{tabular}

Lumped model analysis of piezoelectric structures has received considerable attention since the 1970s, and the formulation presented by Alik and Hughes, based on the variational principle, is widely referenced. For simplicity, the model used in this paper has one degree of freedom. Indeed, a mechanical model based on only one degree of freedom gives a good description of the vibrating piezoelectric transformer behavior near one of its resonant frequencies.

The electric equivalent circuit of the transformer is shown in Figure 2. The circuit consists of a static part, which is represented by the clamped capacitances $C_{1}$ and $C_{2}$, and a resonant branch, which is corresponding to the first mechanical vibration mode. In this equivalent circuit, $n_{1}$ and $n_{2}$ are the mechanical input and output transformation ratio, respectively. In the resonant branch, inductor $L_{\mathrm{m}}$, resistor $R_{\mathrm{m}}$ and capacitor $C_{\mathrm{m}}$ are equivalent to the mass, the mechanical damping, and the stiffness of the first vibration mode, respectively. The current $i_{\mathrm{m}}$ flowing in the mechanical resonant branch is equivalent to the vibration velocity of the structure. The dielectric loss is neglected. 


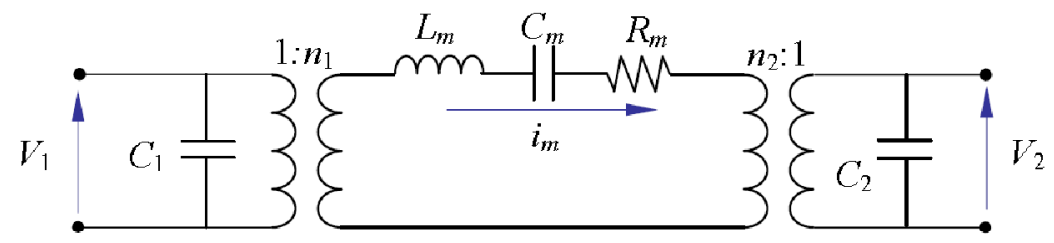

Fig. 2: Equivalent circuit of the piezoelectric transformer

The parameters of the equivalent circuit have been characterized and are summarized in Table 2 . The resonance frequency of the transformer is $82.7 \mathrm{kHz}$.

Table II: Model parameters

\begin{tabular}{|c|c|c|}
\hline Symbol & Description & Value (unit) \\
\hline$f$ & Operating frequency & $82.7 \mathrm{kHz}$ \\
\hline $\mathrm{n}_{2} / \mathrm{n}_{1}$ & Coupling ratio & 1 \\
\hline $\mathrm{C}_{\mathrm{m}}$ & Mechanical capacitance & $92 \mathrm{pF}$ \\
\hline $\mathrm{L}_{\mathrm{m}}$ & Mechanical inductance & $40.3 \mathrm{mH}$ \\
\hline $\mathrm{R}_{\mathrm{m}}$ & Mechanical resistance & $10 \Omega$ \\
\hline $\mathrm{C}_{1}$ & Input capacitance & $20 \mathrm{nF}$ \\
\hline $\mathrm{C}_{2}$ & Output capacitance & $20 \mathrm{nF}$ \\
\hline
\end{tabular}

\section{DC/AC circuit with energy recovery}

The typical topology of PT based DC/DC converter is shown in Fig. 3. The DC/AC input driving circuit excites the PT vibration. Then PT transfers the vibration energy to the output terminal. After passing through the rectifier, the DC voltage can be obtained. When the PT operated at fixed frequency, the mechanical current $i_{m}$ in Fig. 2 can be assumed as a pure sinusoidal wave in the steady state. Accordingly, the mechanical current can be viewed as the sinusoidal current source into the rectifier. The rectifier is the typical full-wave rectifier.

The main objective of the this work is to study the input driving circuit (DC/AC converter) to reduce consumption of apparent power, to optimize the active power and to suppress the reactive power at working frequencies close to the resonant one. The main problem is the energy stored in the clamped capacitance $C_{1}$ of the transformer. This energy in capacitance is a reactive energy that must be managed to avoid to oversize the power supply. In addition, a square-driving signal will generate large losses in the switches. Therefore, a series or parallel inductor is typically added to the piezoelectric transformer to ensure the ZVS condition in the power stage, but the inductor is bulky in low frequency application. Accordingly, in this work a new circuit topology is proposed to limited reactive energy and to recover this energy.

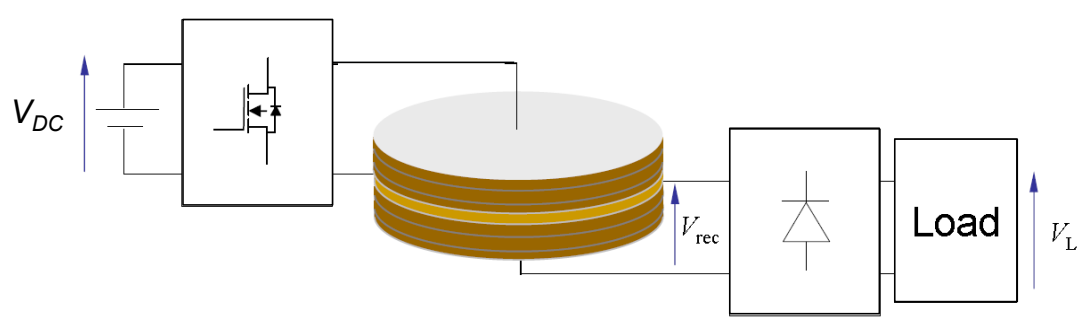

Fig. 3: Diagram of a DC/DC converter with piezoelectric transformer 
The new circuit topology is shown in Figure 4. There are four $n$-channel power MOSFETs switches $K_{1}, K_{2}, S_{1}$ and $S_{2}$. The switches $K_{1}$ and $K_{2}$ are operated as a half-bridge circuit. The transformer with input capacitance $C_{1}$ is connected to the middle point of the switches $K_{1}$ and $K_{2}$. The half-bridge switches generate a trapezoidal waveform of the voltage $v_{l}$ applied to the input terminal of the transformer. The input voltage $v_{l}$ excites the mechanical vibration and induces the input current $i_{p}$. The vibration velocity of the transformer is equivalent to a virtually mechanical current $i_{m}$. Switches $S_{1}, S_{2}$ and inductor $L$ are also connected to the input terminal of the transformer. These shunt circuit is only switched-on during the dead time of the half-bridge for the recovery energy purpose. In practice, inductor $L$ is small, so there is no bulk inductor in the implemented circuit. For simplicity, there are some assumptions for the understanding of this circuit: the parasitic capacitors of switches are neglected, as they do not influence the ZVS condition mainly leaded by the capacitance of the transformer.

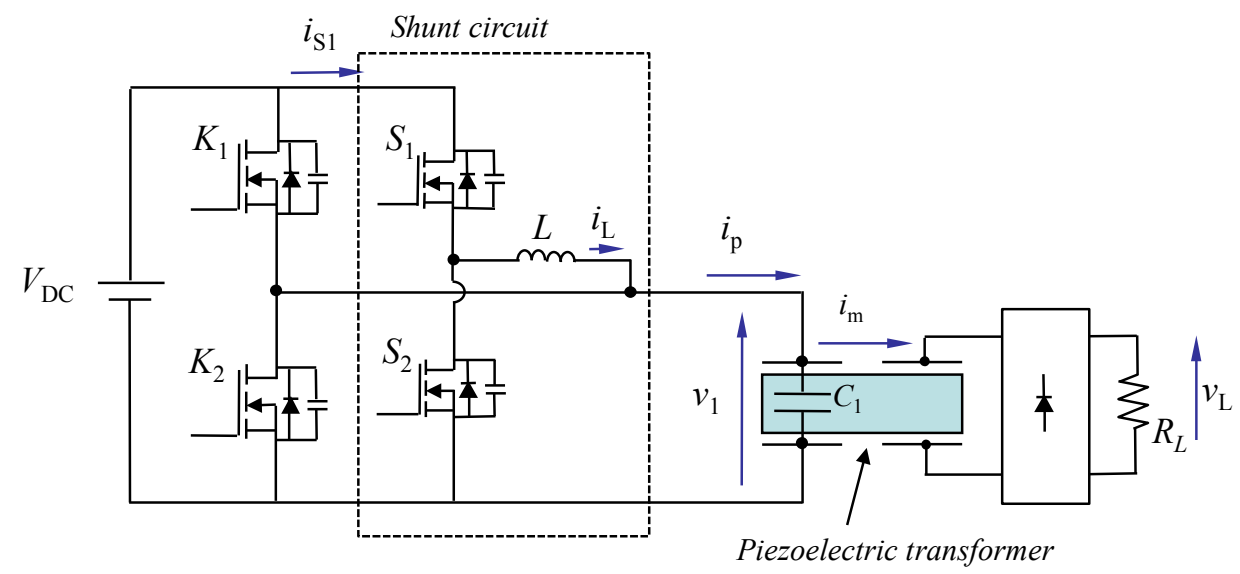

Fig. 4: Circuit topology of DC/AC proposed converter

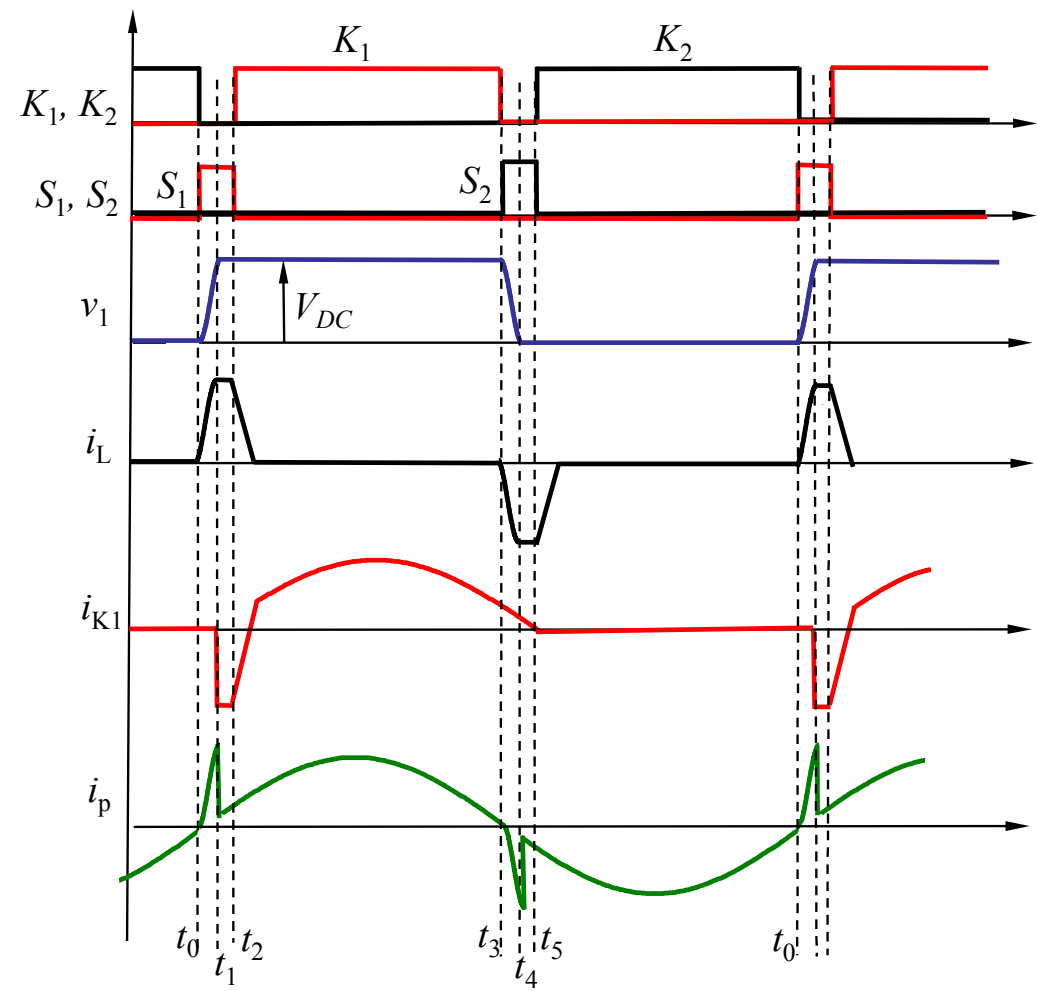

Fig. 5: Theoretical waveforms 


\section{Principle of operation}

The principle of operation is explained with the aid of the ideal key-waveforms of the driving circuit operating at resonance frequency of transformer (Fig. 5). The circuit operation is mainly categorized into six steps:

Step $1\left[t_{0}<t<t_{1}\right]$ Figure 6-a: The high-side switch $S_{1}$ is ON and the switches $K_{1}, K_{2}$ and $S_{2}$ are OFF. The capacitor $C_{1}$ is charged through the inductor $L$. It should be noted that capacitor $C_{1}$ contribute to the resonance with inductor $L$ in this step. Voltage $v_{l}$ increases sinusoidally until reaching $V_{\mathrm{DC}}$ and the current in inductor $L$ increases until reaching $V_{D C} \sqrt{C_{1} / L}$. This step is the key of the ZVS condition for the low-side switch $K_{1}$. If the charging time during the period is not large enough, capacitor $C_{1}$ cannot be fully charged to $\mathrm{V}_{\mathrm{DC}}$ and the high-side switch $K_{1}$ cannot be turned $\mathrm{ON}$ at zero voltage in the following step. Therefore, this step must be larger than the period of resonance between $L$ and capacitance $C_{1}$ :

$$
t_{1}-t_{0}=\frac{\pi}{2} \sqrt{L C_{1}}
$$

which is a quarter of the resonant period of the $\mathrm{L}_{-} \mathrm{C}_{1}$ series resonant circuit. According to Eq. (1), a small inductance is required with the small time interval $\left(t_{1}-t_{0}\right)$ under the given capacitances. This is the underlying reason why we can adopt a small value inductance. This step is over when capacitor voltage reaches $\mathrm{V}_{\mathrm{DC}}$, the body diode $D_{1}$ of switch $K_{1}$ automatically turns on and keeps the voltage across the capacitor at $\mathrm{V}_{\mathrm{DC}}$.

Step 2. [t $1<t<t 2]$ Figure 6-b: During this step, switch $S_{1}$ is still $\mathrm{ON}$ and the switches $K_{1}, K_{2}$ and $S_{2}$ are still OFF. The input voltage $v_{l}$ is equal to $\mathrm{V}_{\mathrm{DC}}$. During this period, the body diode $D_{1}$ of switch $K_{1}$ is forward bias in order to support current $i_{\mathrm{L}}$. The current in the inductor $L$ will free wheel around the $\mathrm{S}_{1}$ L-D $\mathrm{D}_{1}$ loop. This step is over until switch $K_{1}$ is turned ON and $S_{1}$ is turned OFF.

Step 3. $[t 2<t<t 3]$ Figure 6-c: The high-side switch $K_{1}$ is ON and the low-side switch $K_{2}$ is OFF. The shunt circuits $S_{1}$ and $S_{2}$ are both OFF. During this period, the body diode of switches $K_{1}$ and $S_{2}$ are forward bias in order to support current $i_{L}$ flowing back to power supply decreasing in time at a rate $L \frac{d i}{d t}=V_{D C}$. The energy stored in the inductor $L$ can be recovered to the power supply. In the same time, the sinusoidal mechanical current $i_{\mathrm{m}}$ is flowing through the switch $K_{1}$ and the transformer.

Step 4. $\left[t_{3}<t<t_{4}\right]$ Figure 6-d: The high-side switch $K_{1}$ is OFF and the low-side switch $S_{2}$ is ON. The capacitor $C_{1}$ is discharged through the inductor $L$. The discharge time is a quarter of the resonance period of the $\mathrm{L}-\mathrm{C}_{1}$ resonance circuit. This step is over when capacitor voltage reaches 0 , body diode $D_{2}$ of switches $K_{2}$ automatically turns on. It is similar as step 1.

Step 5. $\left[t_{4}<t<t_{5}\right]$ Figure 6-e: During this step, switch $S_{2}$ are still ON. The body diode $D_{2}$ of switch $K_{2}$ is forward bias in order to support current $i_{\mathrm{L}}$. The current in the inductor $L$ will free wheel around the $\mathrm{S}_{2}-$ L-D ${ }_{2}$ loop. This step is over until switch $K_{2}$ is turned ON and $S_{2}$ is turned OFF. It is similar as step 2 .

Step 6. $\left[t_{5}<t<t_{0}\right]$ Figure 6-f: The high-side switch $K_{1}$ is OFF and the low-side switch $K_{2}$ is ON. The shunt circuits $S_{1}$ and $S_{2}$ are both OFF. During this period, the body diode of switches $K_{2}$ and $S_{1}$ are forward bias in order to support current $i_{L}$ flowing back to power supply, decreasing in time at a rate $L \frac{d i}{d t}=V_{D C}$. The energy stored in the inductor $L$ can be recovered to the power supply. In the same time, the sinusoidal mechanical current $i_{\mathrm{m}}$ is flowing through the switch $K_{2}$ and the transformer.

In brief summary, the main power switches $K_{1}$ and $K_{2}$ are turned ON in steps 3 and 6 respectively. During the other steps, switches $K_{1}$ and $K_{2}$ are both OFF, which are the dead time in the half-bridge circuit. In steps 1 and 4 the capacitor of the transformer is resonantly charged or discharged by the shunt circuits to achieve the ZVS conditions. Once they are achieved, the currents in the inductor of the shunt circuit are recovered in steps 3 and 6 . 


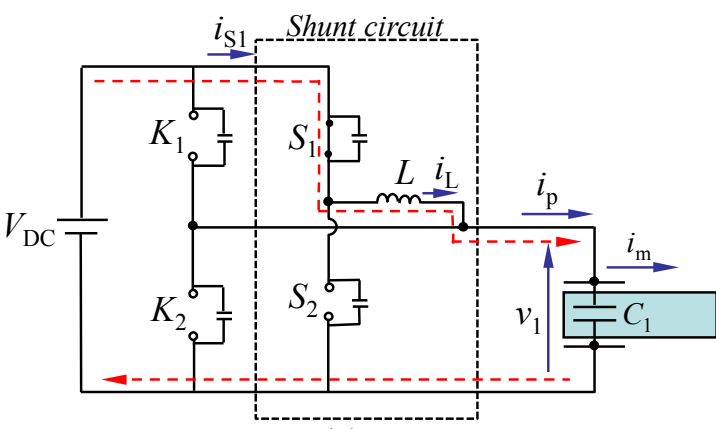

(a)

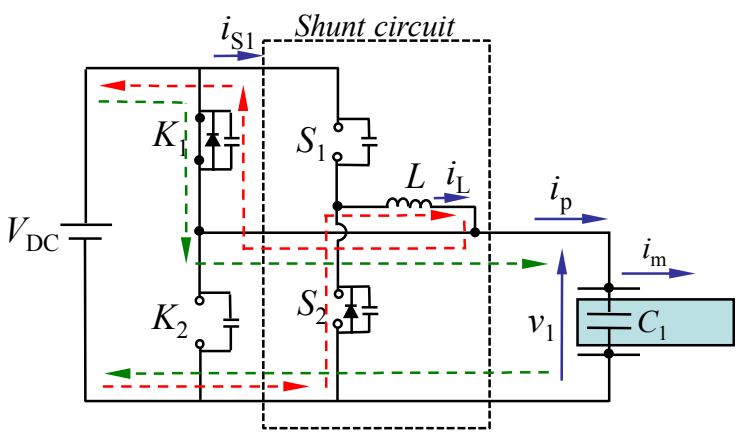

(c)

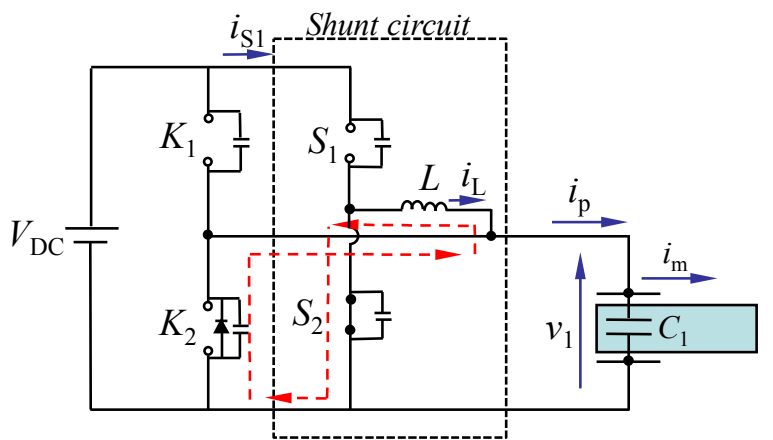

(e)

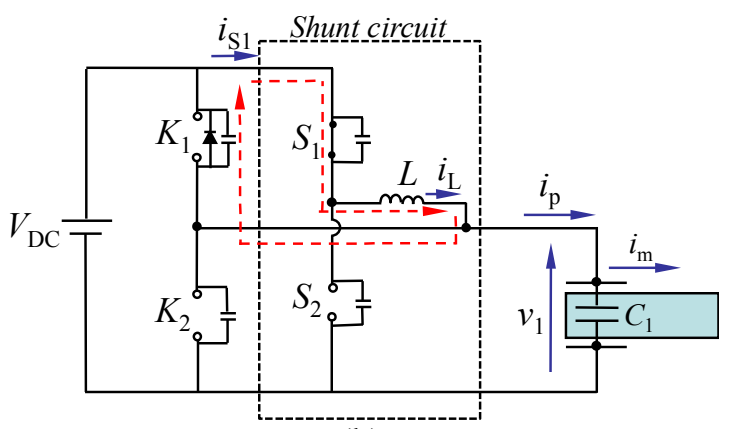

(b)

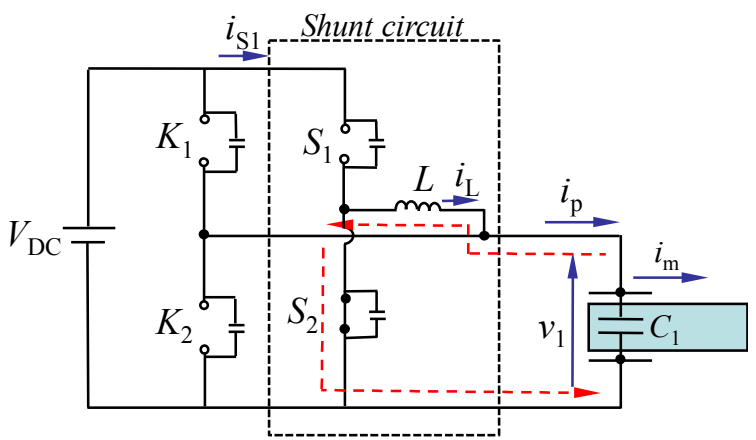

(d)

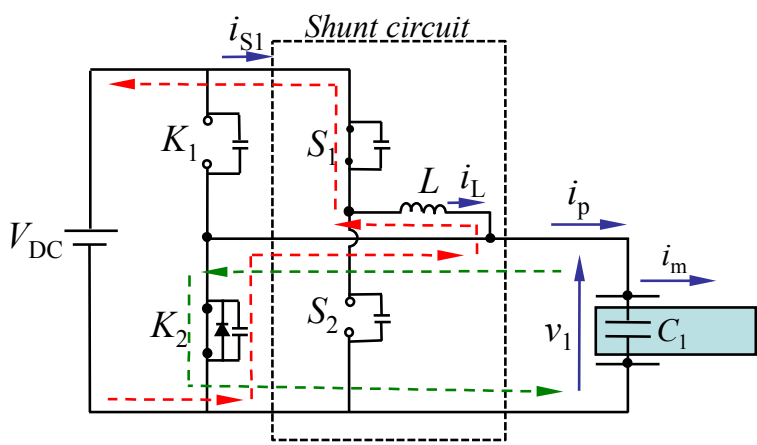

(f)

Fig. 6: Equivalent circuits of proposed DC/AC converter in different steps (a) Step $1\left[\mathrm{t}_{0}-\mathrm{t}_{1}\right]$ (b) Step 2 $\left[\mathrm{t}_{1}-\mathrm{t}_{2}\right]$ (c) Step $3\left[\mathrm{t}_{2}-\mathrm{t}_{3}\right]$ (d) Step $4\left[\mathrm{t}_{3}-\mathrm{t}_{4}\right]$ (e) Step $5\left[\mathrm{t}_{4}-\mathrm{t}_{5}\right]$ (f) Step $6\left[\mathrm{t}_{5}-\mathrm{t}_{0}\right]$

\section{Optimal value of inductor}

To optimize the reactive energy in the system witch decrease the input power source and in the same time to decrease the size of the inductor, the amplitude of the input current must be limited. In other words, the amplitude of current in auxiliary shunt circuits must be the same than the fundamental current at resonance of piezoelectric transformer. The amplitude of current in auxiliary shunt circuit is given by the resonance between $L$ and $C_{1}, I_{S}^{M a x}=V_{D C} \sqrt{C_{1} / L}$. At the resonance the power supplied by the amplifier is given by:

$$
P_{\text {piezo }}=V_{1}^{R M S} I_{P}^{R M S}=\frac{2 V_{D C}}{\pi \sqrt{2}} \cdot \frac{I_{m}^{M a x}}{\sqrt{2}}
$$

Where $V_{1}^{R M S}$ and $I_{P}^{R M S}$ are the RMS value of the fundamental of the voltage $v_{l}$ and the RMS value of the piezoelectric mechanical current at the resonance respectively. $I_{m}^{\operatorname{Max}}$ is the magnitude of the mechanical current at the resonance. $P_{\text {piezo }}$ is the active power at the input of the piezoelectric 
transformer $P_{\text {piezo }}=\frac{2 V_{D C} I_{m}^{M a x}}{\pi}$. The optimal inductor is obtained when the magnitude of the current in auxiliary circuit is equal to magnitude of the mechanical current at the resonance.

$$
L=C_{1}\left(\frac{V_{D C}}{I_{m}^{M a x}}\right)^{2}
$$

\section{Experimental results}

The experimental setup is shown in Figure 8, in which the tested piezoelectric transformer is shown Figure 1. The signal processing to generate pulse to drive the switches is performed by two monostables and two xor (Figure 7). All measuring signals are simply monitored using an oscilloscope. The following specifications and components were adopted in our experiment: $V_{\mathrm{DC}}=15 \mathrm{~V}$; the four switches $K_{1}, K_{2}, S_{1}$ and $S_{2}$ : IRF 640 ; load resistor $R_{\mathrm{L}}=22 \Omega$; constant dead time, i.e. $\left(\mathrm{t}_{2}-\mathrm{t}_{0}\right)$ and $\left(\mathrm{t}_{5}-\mathrm{t}_{3}\right): 0.8 \mu \mathrm{s}$. The inductor value has been set in order to limit the spike current during quarter-period of the resonant instant (when the piezoelectric voltage changes from 0 to $V_{D C}$ and from $\mathrm{V}_{\mathrm{DC}}$ to 0 ) using equation (3). The objective is to minimize the apparent power, which appear when the piezoelectric clamped capacitance is charging or discharging. According to the value of clamped capacitance of $20 \mathrm{nF}$, a good performances are obtained with an inductor value of $5 \mu \mathrm{H}$. All component values are shown in table 3 .

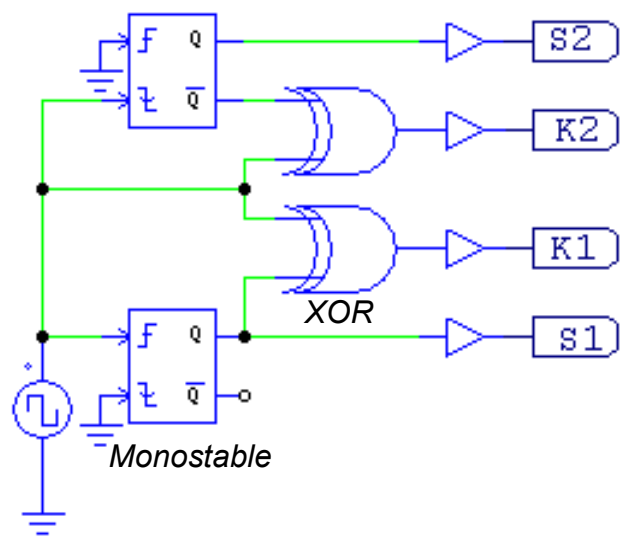

Fig. 7: Signal processing to drive switches

Table III: Component values

\begin{tabular}{|c|c|c|}
\hline Symbol & Description & Value (unit) \\
\hline$K_{1}, K_{2}, S_{1}, S_{2}$ & Transistors MOSFET & IRF 640 \\
\hline$L$ & Inductor & $5 \mu \mathrm{H}$ \\
\hline $\mathrm{V}_{\mathrm{DC}}$ & Input voltage & $15 \mathrm{~V}$ \\
\hline$C_{1}$ & Piezoelement capacitance & $20 \mathrm{nF}$ \\
\hline $\mathrm{t}_{2}-\mathrm{t}_{0} \& \mathrm{t}_{5}-\mathrm{t}_{3}$ & Dead time & $0.8 \mu \mathrm{s}$ \\
\hline & Monostable & 4538 \\
\hline & XOR & 4070 \\
\hline & MOS Driver & IRF 2108 \\
\hline
\end{tabular}


Figures 9 to 11 show the experimental waveforms of $S_{1}$ and $S_{2}$ driving signals, piezoelectric voltage $v_{1}$, inductor current $i_{L}$, and piezoelectric current $i_{P}$ at the mechanical resonance $82.7 \mathrm{~Hz}$. It can be seen that the experimental waveforms are in excellent agreement with the theoretical and simulation predictions. We have tested the converter with frequency range from $60 \mathrm{kHz}$ to $100 \mathrm{kHz}$ and a constant dead time, i.e. $0.8 \mu$ s. The experimental results have verified that the proposed circuit can recover energy in a wide bandwidth without the use of a bulky inductor and thanks to a minor complication of the circuit with ancillary low losses semiconductors. The analysis of these figures leads to conclude that the auxiliary circuits, during dead time, charge and discharge the clamped capacitance trough inductor which justifies the reduction of the power consumption.

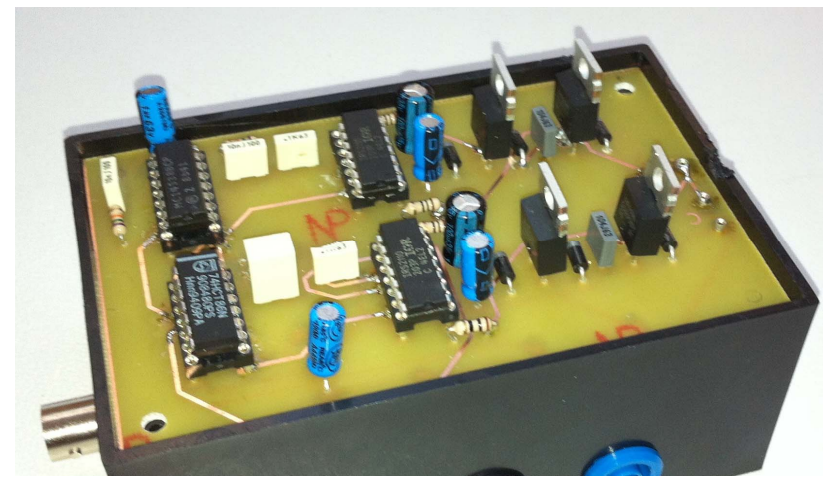

Fig. 8: Picture of the proposed DC/AC converter

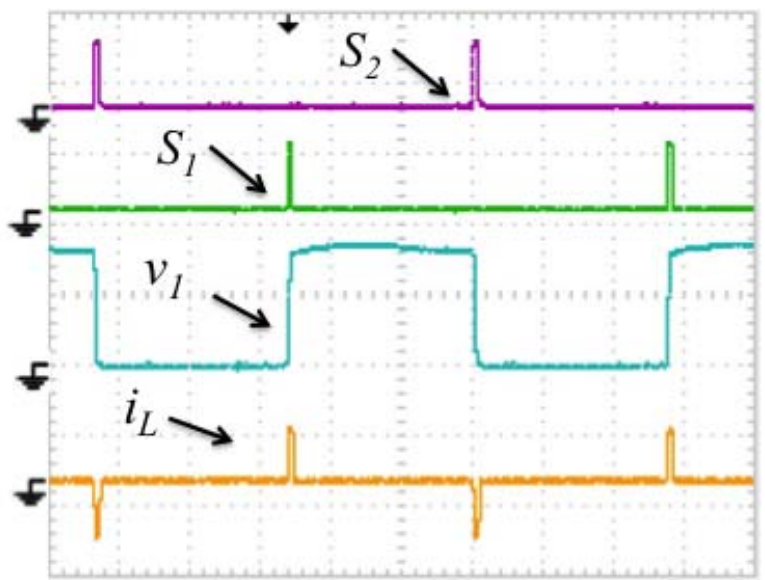

Fig. 9: Experimental waveforms: $\mathrm{S}_{2}$ drive signal $(10 \mathrm{~V} / \mathrm{div}), \mathrm{S}_{1}$ drive signal $(10 \mathrm{~V} / \mathrm{div})$, voltage $\mathrm{v}_{1}$ $(10 \mathrm{~V} /$ div $)$ and current $\mathrm{i}_{\mathrm{L}}(500 \mathrm{~mA} / \mathrm{div})$

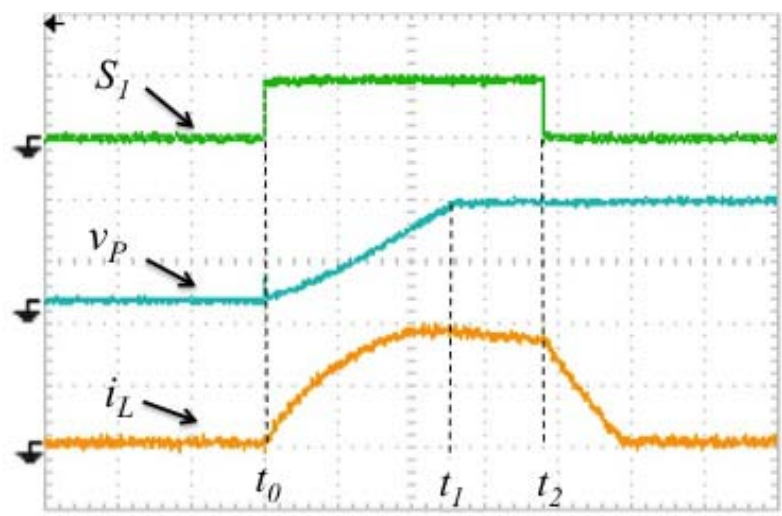

Fig. 10: Experimental waveforms during dead-time, i.e. $\left(\mathrm{t}_{2}-\mathrm{t}_{0}\right)$ : $\mathrm{S}_{1}$ drive signal $(10 \mathrm{~V} / \mathrm{div})$, voltage $\mathrm{v}_{1}$ $(10 \mathrm{~V} / \mathrm{div})$, current $\mathrm{i}_{\mathrm{L}}(200 \mathrm{~mA} / \mathrm{div})$ and time $(2 \mu \mathrm{s} / \mathrm{div})$ 


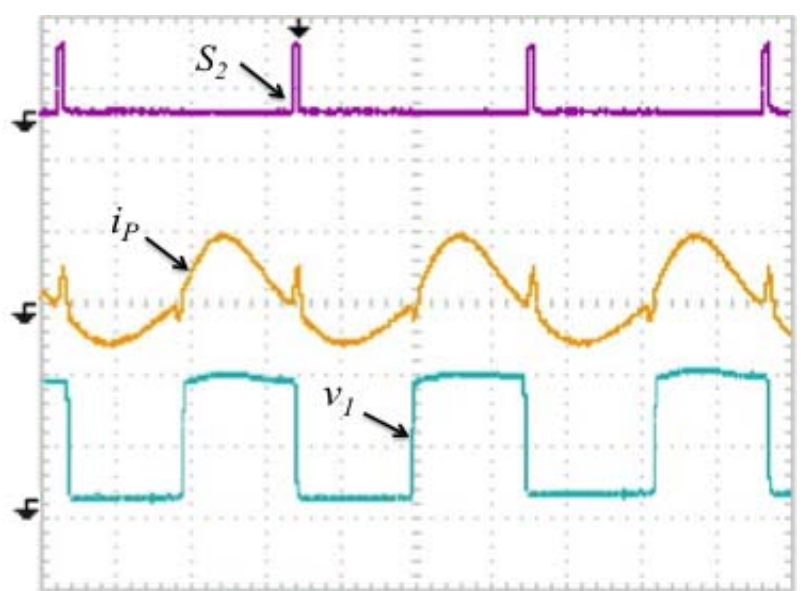

Fig. 11: Experimental waveforms: $S_{2}$ drive signal $(10 \mathrm{~V} /$ div $)$, current $i_{P}(500 \mathrm{~mA} /$ div $)$ and voltage $v_{1}$ (10V/div)

The experimental value of $\left(t_{1}-t_{0}\right)$ which is quarter of the resonant period of the $L-C_{1}$ series resonant circuit is $0.5 \mu \mathrm{s}$. Figure 12 shows the experimental active power versus frequency. The maximum power transmitted at the resonance is $3.9 \mathrm{~W}$.

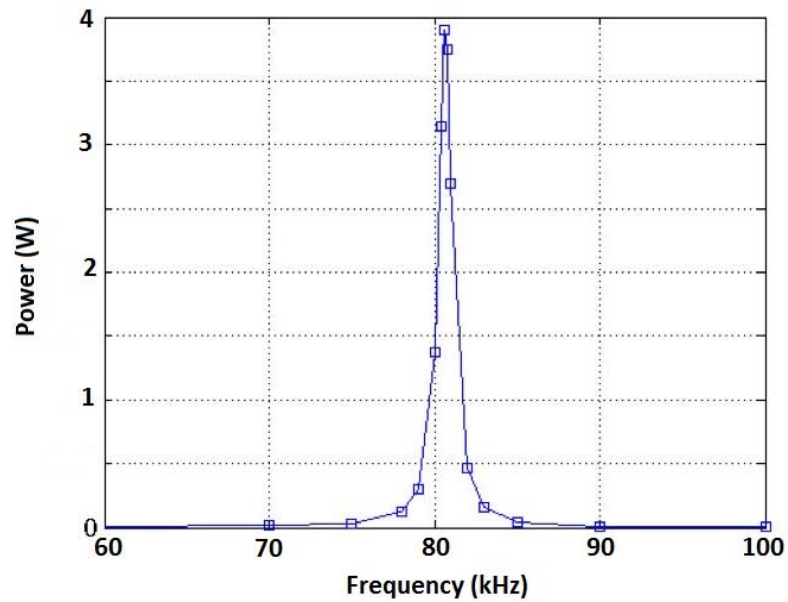

Fig. 12: Experimental output power 


\section{Conclusion}

A new circuit for driving a piezoelectric transformer with quasisquare waveforms has been presented analytically and verified experimentally and includes recovery of the electrical energy stored in the capacitance of the piezoelectric transformer back to the primary power supply. A shunt circuit is connected to the input terminal to the transformer in order to enlarge the ZVS bandwidth of the typical half-bridge driving circuit. Since the ZVS condition can be achieved without any bulky inductor, the proposed circuit may be significantly smaller, which could be an advantage in some applications.

\section{References}

[1] Steltz E., Seeman M., Avadhanula S., and Fearing R. S.: Power electronics design choice for piezoelectric microrobots, IEEE/RSJ Int. Conf. on Intelligent Robots and Systems, pp. 1322-1328, 2006

[2] Hollar S., Flynn A., Bellew C., and Pister K. S. J.: Solar powered $10 \mathrm{mg}$ silicon robot, IEEE Sixteenth Annual Int. Conf. on Micro Electro Mechanical Systems, pp. 706-711, 2003

[3] Kornbluh R. D., Pelrine R., Pei Q., Heydt R., Stanford S.; Oh S., Eckerle J.: Electroelastomers: Applications of dielectric elastomer transducers for actuation, generation, and smart structures, SPIE, vol. 4698, pp. 254-270, 2002

[4] Wood R. J.: Liftoff of a 60mg flapping-wing MAV, IEEE/RSJ Int. Conf. on Intelligent Robots and Systems, pp. 1889-1894, 2007

[5] Wang Q., Du X., Xu B., and Cross L.: Theoretical analysis of the sensor e_ect of cantilever piezoelectric benders : J. of Aplied Physics, vol. 85, pp. 1702-1712, 1999

[6] Wood R. J., Steltz E., and Fearing R. S.: Optimal energy density piezoelectric bending actuators, Sensors and Actuators: A. Physical, vol. 119, no. 2, pp. 476-488, 2005

[7] Robbins P. W.: Simplified Unipolar, Quasisquare Wave Energy Recovery Drive Circuits for Piezoelectric Actuators, IEEE Trans. Ultrason., Ferroelectr., Freq. Control, vol. 52, no. 8, 2005

[8] Karpelson M., Wei G.Y., Wood R. J.:Driving high voltage piezoelectric actuators in microrobotic applications, Sensors and Actuators A, vol. 176, pp. 78- 89, 2012

[9] Liu Y.P., Vasic D., Costa F.: Wideband ZVS half-bridge circuit for piezoelectric transformers with small inductance, Electronics Letters, vol. 48, no. 9, pp.523-524, 2012

[10] Liu Y.P., Vasic D., Wu W.J., Costa F., and Lee C.K: Design of fixed-frequency controlled radial-mode stacked disk-type piezoelectric transformers for DC/DC converter application, Smart Materials and Structures, vol. 18, no.8, 085025, 2009

[11] Vasic D., Costa F., Sarraute E.: A new MOSFET \& IGBT gate drive insulated by a piezoelectric transformer, IEEE PESC 2001, Vancouver, Canada, 2001

[12] Su Y.H., Liu Y.P., Vasic D., Wu W.J., Costa F., Lee C.K.: Study of Piezoelectric Transformer-Based DC/DC Converter with cooling system and Current-Doubler Rectifier, Smart Materials and Structures, Vol. 22, no. 9, 095005, 2013

[13] Vasic D., Liu Y.P., Schwander D., Costa F., Wu W.J.: Improvement of Burst-Mode Control of Piezoelectric Transformer-based DC/DC Converter, Smart Materials and Structures, Vol. 22, no. 5, 055020, 2013

[14] Liu Y.P., Vasic D., Costa F., Wu W.J.: Electromagnetic Interferences Analysis of DC/DC Converters Based on Piezoelectric Transformers, Japanese Journal of Applied Physic, Vol. 49, no. 6, 061501, 2010

[15] Vasic D., Costa F., Sarraute E.: Comparing piezoelectric and coreless electromagnetic transformer approaches in IGBT driver. The European Physical Journal Applied Physics, Volume 34, Issue 3, pp. 237-242, June 2006

[16] Vasic D., Costa F., Sarraute E.: Piezoelectric Transformer for Integrated MOSFET \& IGBT Gate Driver. IEEE Transactions on Power Electronics, Volume 21, Issue 1, pp. 56-65, January 2006

[17] Lin R.L.: Piezoelectric transformer characterization and application of electronic ballast, PhD Dissertation Virginia Polytechnic Institute and State University, USA, 2001 